\title{
FASHION RETAIL COMPETITION ON PRODUCT GREENNESS WITH OVERCONFIDENCE
}

\author{
Bayi Cheng ${ }^{1,2, *}$, Yuqi Wang ${ }^{1,2}$, Xinyan Shi ${ }^{1,2}$ and Mi Zhou ${ }^{1,2}$
}

\begin{abstract}
In this paper, we study the impacts of overconfidence in a competitive retailer setting of green fashion. We model a green fashion supply chain comprising one unbiased manufacturer and two biased retailers, to explore how overconfidence affects greenness level of fashion products and expected profit of retailers. An overconfident retailer has a cognitive bias in which it believes consumers are more sensitive to greenness of fashion products than it really is. Our findings show that the competition between two retailers discourages greenness level of fashion products, while overconfidence can provide a counterbalance to the negative impact caused by competition. We also find, a retailer's overconfidence is not only conducive to the greenness level of its own fashion products, but also can benefit to its rival. Moreover, it shows a low level of overconfidence can be a comparative advantage of the retailer's profit. Even though one of the retailers is unbiased and has an advantage of information, it can still earn less than its overconfident rival.
\end{abstract}

Mathematics Subject Classification. 00A06.

Received June 17 2021. Accepted November 29, 2021.

\section{INTRODUCTION}

In the context of sustainable economic development, environmental pollution is attracting more and more attention. The public is concerned that the fashion industry is a source of pollution. In fact, fashion industry is known as the second largest polluter, after the oil. The production of fashion products has caused terrible pollution problems such as high carbon emissions, toxic gases, waste water production, large amounts of landfill waste, excessive packaging and employing energy. According to the United Nations figures for 2018, the fashion industry emits $20 \%$ of the world's waste water every year, and releases $10 \%$ of carbon dioxide, more than all international flights and ocean shipping emissions combined. Every year, 500000 tons of fine plastic fibers are discharged into rivers and seas during the washing of synthetic materials such as polyester, nylon and acrylic. Therefore, it is urgent to develop green products with cleaner processes in the fashion industry.

Moreover, sustainability is becoming an increasingly important variable as consumers make fashionpurchasing decisions. The increasing demand for sustainability in fashion is being driven first and foremost by consumers, an increasing number of customers are willing to purchase green products, so in the fashion busi-

Keywords. Overconfidence, retail competition, green fashion.

1 School of Management, Hefei University of Technology, Hefei 230009, P.R. China.

2 Key Laboratory of Process Optimization and Intelligent Decision-making, Ministry of Education, Hefei 230009, P.R. China.

* Corresponding author: chengbayi@hotmail.com 
ness world, product greenness competition is prevailing, "green" has become the primary consideration for most designers. For the fashion industry, the enhancement of product greenness is not only the external requirement of sustainable development, but also an internal important tool to achieve stable competitiveness.

However, in the process of greening fashion industry, managers may make decisions with overconfidence. A number of behavioral researches have found that decision making will be heavily affected by cognitive biases such as overconfidence, fairness preference, loss aversion etc, and overconfidence is one of the most prevalent cognitive biases. Additionally, green fashion managers are more likely to have an overconfident bias that consumers are more sensitive to greenness of fashion products than it really is. Even though consumers demonstrate a high degree of environmental attitude, they rarely translate their sustainability-oriented intentions into green purchasing actions. One recent survey has revealed that $65 \%$ consumers expressed they'd like to buy green products, yet only about 26 per cent consumers actually do so [31].

This phenomenon is also evident in the green fashion industry. Fashion is highly symbolic, it allows consumers to express present and ideal self. The existing researches $[8,17,26,30,32]$ have pointed out most fashion consumers have positive attitudes about green fashion, yet they still often hesitate to sacrifice their fashion desires and preferences for the sake of being green. It is an ongoing frustration for green fashion research and practice that consumers do not walk their talk within the fashion industry, and the inconsistency between attitude and behavior of fashion consumers could cause managers to have a bias that consumers are more sensitive to greenness of fashion products than it really is. In other words, they're more likely to overestimate the impact of greenness on products' demand.

Motivated by the above phenomenon, we present a study on the effects of overconfidence in the green fashion industry. This paper models a green fashion supply chain comprising one unbiased manufacturer and two biased retailers, to explore how overconfidence would affect greenness level of fashion products and resulting expected profit of retailers in a competitive setting.

We find that the retailers' overconfidence can provide a counterbalance to the negative impact of competition on products' greenness, and the retailer's overconfidence is not only conducive to the greenness level of their own fashion products, but also benefits to its rival's products' greenness. Moreover, an overconfident retailer is not always destined to earn lower expected profit than unbiased one, if overconfidence is at a low level, this bias boosts optimal resulting expected profit of the retailer. Similarly, we demonstrate that if a fashion retailer in the competitive setting has a low level of overconfidence, the two retailers' biases both benefit the retailer's profit. Furthermore, we show that the advantage attributed to this bias is still work even though one of the fashion retailers is unbiased and has an advantage of information, it can still earn less than its overconfident rival.

The remainder of the paper is organized as follows. In Section 2, we present literatures related to our work, and propose our contributions. In Section 3, we describe the model. In Section 4, we consider four scenarios to examine the impacts of overconfidence. In Section 5, we make a conclusion.

\section{Literature REVIEW}

First, our work is related to the studies on sustainable supply chain management. By analysing OR/MS reviews, Romero Silva and de Leeuw [28] and Merigó [23] reveal that green and sustainable supply chain have received significant attention from researchers. Reefke and Sundaram [27] confirm and extend knowledge on sustainable supply chain management. Liu et al. [22] compare the impacts of retail price and competition, in their study, there are two green supply chains which compete on carbon emission reduction, they investigate how retail price and competition affect supply chain system profit and products' demand. Yang et al. [35] formulate a game model which consists of a government and two competing firms, to investigate two symmetric firms' technology improvement strategies, and analyze the role of government subsidy. Izabela et al. [10] explore the optimal pricing and investment decision for two competing green supply chains, and search if the strategic integration decision has effects on green products' types. Zhu and Wu [39] develop a supply chain comprising one manufacturer and two asymmetric retailers to explore the effects of retailers' strategic decisions on the 
introduction of a newer green product. Li et al. [20] study the diffusion performance of green competitive products with considering consumer networks by using an experimental method.

Second, our work is closely related to the studies on green fashion and fashion supply chain management. Ding [6] analyzes the issues of Going Green Fashion Design by making researches on ecological materials and fabrics, virtual efforts, and wearing methods. By using the theory of consumer behaviour, Cowan and Kinley [5] identify the factors influencing green apparel purchase intentions. Kim et al. [14] focus on a fashion brand in Patagonia to study green marketing advertising in the fashion industry. Fung et al. [7] identify the supply chain structures and essential steps in fashion products development processes, they analyze the key factors of achieving sustainable fashion and establish a sustainable product development process matrix, which can guide the fashion supply chain members to operate in a sustainable way. Moon et al. [24] develop guidelines for the design and production of sustainable energy-saving fashion products (ESFPs). It enables enterprises to obtain a deeper understanding of the green demands and provides designers with a reference of ESFPs to meet the specific needs of different customers. Zhu and He [39] investigate the green product design issues in supply chains under competition, they find that decisions on greenness level are affected by factors such as supply chain structures, the green product types, and the types of competition. Guo et al. [9] develop a model consisting of one manufacturer and two competing retailers in a fashion supply chain, to investigate the implication of retail competition and consumer returns on green products development.

Third, our work is closely related to the literature on overconfidence. Xiao [33] studies how the overconfidence of supply chain members affects their inventory management decisions and suppliers' quality investment in a supply chain. Chen et al. [3] consider a supply chain composed of rational manufacturers and overconfident sellers to study how manufacturers make production decisions and pricing of products, and design appropriate incentive mechanisms to motivate sellers. Yu and Zhou [36] formulate a contract model of a supply chain in which one rational supplier and one overconfident retailer under uncertain conditions. Cheng and Li et al. [4] discuss the order decision-making in a supply chain comprising a mass customization manufacturer and overconfident retailers.

Li et al. [19] argue the implications of newsvendors' overconfidence in a competitive setting, they find overconfidence can benefit to the outcome when the product's profit margin is high, and the more biased of two competing newsvendors may earn less than its less biased competitor. Kirshner and Shao [15] develop a model to confirm the effects of optimism and overconfidence in a price-setting newsvendor problem, they conclude that optimism increases inventory and it tends to lead to a lower price, they also show that overconfidence and regret have similar effects on both pricing and order quantities. Li [18] develops a distribution channel comprising one manufacturer and one retailer with overconfidence, he finds that overconfidence can benefit to channel performance and members. $\mathrm{Xu}$ and Liu [34] consider overconfidence in the distribution supply chain, they employ a principal-agent model to obtain the optimal franchise fee contract of overconfident retailers. Li et al. [21] argue the implication of transshipment between overconfident newsvendors, they reveal that although transshipment can be beneficial to the performance of unbiased newsvendors, it may hurt overconfident newsvendors. Jiang and Liu [11] discover that in a competitive market, the optimism about demand of one firm can make more profit for two firms, but the optimism would discourage firms' performance if the managers of two firms are both optimistic. Jin et al. [12] examine the impacts of green optimism in a sustainable supply chain, and find managers' optimistic bias about consumers' willingness to buy green products is deleterious to green product investment, stakeholders and the upstream manufacturer, but might be beneficial to the downstream retailer.

This paper contributes to extant researches in two ways. First, we enrich the green fashion literature by incorporating the notion of overconfidence. Green fashion managers are more likely to have an overconfident bias, so it'd be useful to argue the impacts of this bias on green fashion managers' decisions and performance. We find that the bias about overestimating the impact of greenness on demand can always promote greenness level of fashion products, and the retailer's overconfidence is not only conducive to the greenness level of their own fashion products, but also benefits to its rival. Moreover, if overconfidence is at a low level, an overconfident retailer can earn higher profit than the unbiased one. Even if one of the retailers is unbiased and has an advantage of information, it can still earn less than its overconfident rival. 
Second, we consider a competitive retailer setting of the green fashion supply chain by considering two fashion retailers compete on products' greenness, and discuss the impacts of competition and overconfidence. We find that the competition is detrimental to fashion products' greenness, while the fashion retailer's overconfidence can provide a counterbalance to the negative impact of competition, and if the retailer has a low level of overconfidence, the two retailers' biases can both improve its performance.

\section{Model AND NOTATiOnS}

In this paper, we consider a model of a fashion supply chain comprising one manufacturer and two competing retailers. The two fashion retailers, acting as powerful Stackelberg leaders, determine the greenness level of their similar products. The common manufacturer, acting as a Stackelberg follower, decides the wholesale price according to the greenness level of retailers' products.

Consistent with prior competition literature $[2,9,13]$, we assume the greenness-dependent demand function of retailer $i$ is represented by

$$
q=a+g_{i}-\lambda g_{3-i}+\varepsilon
$$

where $a$ represents the primary market scale of the products offered by retailers, it is determined by factors such as products type, selling price, and brand image. Following Guo et al. [9], we assume $a_{1}=a_{2}=a$, that is, retailer $i$ and its opponent retailer $3-i$ have the same primary market sizes. The market demand follows a linear function of products' greenness, as the greenness level $g_{i}$ increases, the market demand of products offered by retailer $i$ increases from its base value at the rate of 1 ; and as the competitor's fashion products' greenness level $g_{3-i}$ increases, the market demand decreases from its base value at the rate of $\lambda$, where $\lambda$ is the negative sensitivity of the retailer $i$ 's market demand caused by its competitor, $\lambda \epsilon[0,1]$. $\varepsilon$ is a random interference term, reflecting the uncertainty of demand, it is a continuous random variable and follows a random distribution with the mean value of 0 , variance of $\sigma^{2}$.

Then, we incorporate the notion of overconfidence into the model. The parameter $\alpha_{i}$ is our measure of overconfidence, $\alpha_{i}$ ranges from 0 to 1 . The bigger $\alpha_{i}$ is, the more overconfident retailer $i$ is. In the extreme, $\alpha_{i}=0$ denotes that retailer $i$ is unbiased. At the other extreme, the retailer $i$ is completely overconfident when $\alpha_{i}=1$. We assume a retailer is overconfident in two ways. First, an overconfident retailer believes consumers are more sensitive to greenness than it really is, its overconfidence is manifested by overestimating the impact of greenness on demand. Second, an overconfident retailer is excessively precise about the uncertainty of market demand, i.e. it thinks the variance of belief demand is lower than the variance of actual demand. Hence, the greenness-dependent demand function of an overconfident retailer $i$ is

$$
q\left(\alpha_{i}\right)=a+\left(1+\alpha_{i}\right) g_{i}-\left(1+\alpha_{i}\right) \lambda g_{3-i}+\left(1-\alpha_{i}\right) \varepsilon
$$

We assume the two fashion retailers wholesale goods at price $w$ and sell goods at price $p$, each retailer has a green product development investment cost $\theta g_{i}^{2} / 2$, it can result from advertising, supervision, and other promotional activities, where $\theta$ is the retail cost coefficient. The manufacturer has its manufacturing costs, we present it by $c$. Accordingly, for achieving a required greenness level, the manufacturer bears an extra unit cost $b g$, that is the manufacturer's development cost of green products, where $b$ is the cost coefficient of green products development.

The game within the fashion supply chain has three stages. In the first stage, the two fashion retailers determine the greenness level of their own products. In the second stage, the manufacturer starts the production activities and decides the wholesale price according to the greenness level of retailers' products. In the third stage, the two fashion retailers determine their ordering quantity.

Table 1 provides a summary of notations used in this paper. 
TABLE 1. Summary of the notations.

\begin{tabular}{ll}
\hline \hline Symbol & Definition \\
\hline$q$ & Market demand of the product offered by the unbiased retailer $i$ \\
$q\left(\alpha_{i}\right)$ & Market demand of the product offered by the biased retailer $i$ \\
$a$ & The primary market scale \\
$\lambda$ & The negative sensitivity of the market demand of retailer $i$ caused by its competitor \\
$\varepsilon$ & A random interference term \\
$\alpha_{i}$ & The overconfidence level of retailer $i$ \\
$w$ & The wholesale price \\
$p$ & The retailers' selling price \\
$\theta$ & The retailers' cost coefficient of green product development \\
$c$ & The manufacturer's manufacturing cost \\
$b$ & The manufacturer's cost coefficient of green products development \\
$g_{i}$ & The unbiased retailer $i$ 's fashion products greenness level \\
$g_{i}(\alpha)$ & The biased retailer $i$ 's fashion products greenness level in the scenario of symmetric overconfidence \\
$g_{i}\left(\alpha_{1,2}\right)$ & The biased retailer $i$ 's fashion products greenness level in the scenario of asymmetric overconfidence \\
$\pi_{r i}$ & The retailer $i$ 's resulting expected profit \\
$\pi_{m}$ & The manufacturer's resulting expected profit \\
$\pi_{r i}(\alpha)$ & The retailer $i$ 's belief expected profit in the scenario of symmetric overconfidence \\
$\pi_{r i}\left(\alpha_{1,2}\right)$ & The retailer $i$ 's belief expected profit in the scenario of asymmetric overconfidence \\
\hline
\end{tabular}

\section{Analysis}

In this section, we first consider a fashion supply chain comprising one rational manufacturer and two unbiased retailers, to examine the impacts of competition. Then, we incorporate the notion of overconfidence, consider overconfidence of two competing retails is symmetric and asymmetric, to investigate the effects of overconfidence. At last, we consider an extreme case by assuming one of the fashion retailers is unbiased and has an advantage of information, while the other one is overconfident.

\subsection{Two unbiased retailers}

In this part, we present the scenario of a fashion supply chain consisting of two unbiased competing retailers and one rational manufacturer. To the unbiased retailer $i$, the demand function is

$$
q=a+g_{i}-\lambda g_{3-i}+\varepsilon .
$$

Thus two fashion competing retailers' resulting expected profit functions are given as follows.

$$
\begin{aligned}
& \pi_{r 1}=\left(p-w_{1}\right)\left(a+g_{1}-\lambda g_{2}\right)-\theta g_{1}^{2} / 2 \\
& \pi_{r 2}=\left(p-w_{2}\right)\left(a+g_{2}-\lambda g_{1}\right)-\theta g_{2}^{2} / 2 .
\end{aligned}
$$

From the manufacturer's perspective, its resulting expected profit function is

$$
\pi_{m}=\left(w_{1}-c-b g_{1}\right)\left(a+g_{1}-\lambda g_{2}\right)+\left(w_{2}-c-b g_{2}\right)\left(a+g_{2}-\lambda g_{1}\right) .
$$

By solving this Stackelberg game, we can obtain the optimal wholesale price and products' greenness level, as follows.

Proposition 4.1. (a) The optimal wholesale price $w^{*}=\frac{\left(1+\frac{b}{\theta}\right)\left(a+\frac{p(1-\lambda)}{\theta}\right)+\left(c+\frac{b p}{\theta} \frac{(1-\lambda)}{\theta}\right)}{2\left(1+\frac{b}{\theta}\right) \frac{1-\lambda}{\theta}}$, the optimal product greenness level $g_{1}^{*}=g_{2}^{*}=\frac{(p-c) / \theta}{2(1+b / \theta)}-\frac{a}{2(1-\lambda)}$. 
(b) The greenness competition decreases the optimal fashion products' greenness level.

Proof. (a) For obtaining the equilibrium outcome, we use backward induction to solve this Stackelberg game. Taking the manufacturer's wholesale price as given, the retailers set the greenness level to maximize their resulting expected profit, and then substituting the optimal greenness level into manufacturer's resulting expected profit function, to obtain the optimal wholesale price.

We first show that there exists a unique solution for a given $g_{i}^{*}$ that maximizes $\pi_{r i}$. The first derivative of $\pi_{r i}$ is $\frac{\partial \pi_{r i}}{\partial g i}=\left(p-w_{i}\right)-\theta g$ and the second derivative is $\frac{\partial^{2} \pi_{r i}}{\partial g^{2}}=-\theta<0$, which implies that $\pi_{r i}$ is concave in $g_{i}$. Thus, the unique optimal value of $g_{i}$, denoted by $g_{i}^{*}$, must satisfy the first order condition $\frac{\partial \pi_{r i}}{\partial g}=0$, from which we obtain $g_{i}^{*}=\frac{\left(p-w_{i}\right)}{\theta}$. Next, we substitute $g_{i}^{*}$ into the $\pi_{m}$, similarly, there exists a unique solution for given $w_{1}^{*}$ and $w_{2}^{*}$ that maximizes $\pi_{m}$, satisfying the first order condition $\frac{\partial \pi_{m}}{\partial w_{1}}=0$ and $\frac{\partial \pi_{m}}{\partial w_{2}}=0$, then, we can obtain the unique optimal value $w_{1}^{*}=w_{2}^{*}=\frac{(1+b / \theta)(a+(p(1-\lambda)) / \theta)+(c+b p / \theta)(1-\lambda) / \theta}{2(1+b / \theta)(1-\lambda) / \theta}$. Substituting the $w_{i}^{*}$ into $g_{i}^{*}=\frac{\left(p-w_{i}\right)}{\theta}$, obtaining the optimal greenness level $g_{1}^{*}=g_{2}^{*}=\frac{\left(p-w_{i}^{*}\right)}{\theta}=\frac{(p-c) / \theta}{2(1+b / \theta)}-\frac{a}{2(1-\lambda)}$.

(b) In the noncompetitive setting, i.e. $\lambda=0$, the optimal greenness level $g^{*}$ of the fashion products provided by one retailer satisfies $g^{*}=\frac{(p-c) / \theta}{2(1+b / \theta)} \cdot g_{1}^{*}=g_{2}^{*}=\frac{\left(p-w_{i}^{*}\right)}{\theta}=\frac{(p-c) / \theta}{2(1+b / \theta)}-\frac{a}{2(1-\lambda)}$, where $\frac{a}{2(1-\lambda)}>0$, it can be obtained that $g^{*}>g_{1}^{*}=g_{2}^{*}$.

According to Proposition 4.1, the optimal greenness level of fashion products $g_{1}^{*}=g_{2}^{*}$ in the competitive setting is lower than the optimal greenness level $g^{*}$ in the noncompetitive setting, it implies that the competition between fashion retailers does not conducive to the improvement of fashion products' greenness level. From this perspective, competition has become an obstacle to the development of greening fashion products.

\subsection{Two homogenous retailers}

In this part, we focus on the scenario of symmetric overconfidence by assuming a common overconfidence level $\alpha_{1}=\alpha_{2}=\alpha$ for the two competing retails. The greenness-dependent demand of retailer $i$ takes the following form.

$$
q=a+(1+\alpha) g_{i}-(1+\alpha) \lambda g_{3-i}+(1-\alpha) \varepsilon .
$$

The homogenous competing two retailers' belief expected profit functions and the manufacturer's expected profit function is given as follows.

$$
\begin{aligned}
\pi_{r 1}(\alpha) & =\left(p-w_{1}\right)\left(a+(1+\alpha) g_{1}-(1+\alpha) \lambda g_{2}\right)-\theta g_{1}^{2} / 2 \\
\pi_{r 2}(\alpha) & =\left(p-w_{2}\right)\left(a+(1+\alpha) g_{2}-(1+\alpha) \lambda g_{1}\right)-\theta g_{2}^{2} / 2 \\
\pi_{m} & =\left(w_{1}-c-b g_{1}\right)\left(a+g_{1}-\lambda g_{2}\right)+\left(w_{2}-c-b g_{2}\right)\left(a+g_{2}-\lambda g_{1}\right) .
\end{aligned}
$$

We use backward induction to solve for the equilibrium outcome.

Proposition 4.2. (a) There exists optimal wholesale price $w_{i}^{*}(\alpha)$ and optimal product greenness levels $g_{i}^{*}(\alpha)$ that maximizes belief expected profit of the manufacturer and two homogenous retailers, characterized by the equations $w_{i}^{*}(\alpha)=\frac{(1+b A)(a+p A-\lambda p A)+A(c+b p A)(1-\lambda)}{2 A(1+b A)(1-\lambda)}$ and $g_{i}^{*}(\alpha)=\frac{A(1-\lambda)(p-c)-a(1+b A)}{2(1+b A)(1-\lambda)}$, where $A=\frac{1+\alpha}{\theta}$;

(b) The optimal product greenness levels $g_{i}^{*}(\alpha)$ of two homogenous retailers is higher than the optimal product greenness levels $g_{i}^{*}$ of two unbiased retailers, i.e. $g_{i}^{*}(\alpha)>g_{i}^{*}$.

Proof. (a) Similar to the proof of Proposition 4.1, we have shown that there exists a unique solution for a given $g_{i}^{*}(\alpha)$ that maximizes $\pi_{r i}(\alpha)$, and the unique optimal value of $g_{i}^{*}(\alpha)$ satisfies the condition $\frac{\partial \pi_{r_{i}}(\alpha)}{\partial g_{i}(\alpha)}=$ $\left(p-w_{i}\right)(1+\alpha)-\theta g_{i}(\alpha)=0$, obtaining the optimal greenness level $g_{i}^{*}(\alpha)=\frac{\left(p-w_{i}\right)(1+\alpha)}{\theta}$.

Next, we substitute $g_{i}^{*}(\alpha)$ into the $\pi_{m}$, similarly, there exists a unique solution for given $w_{1}^{*}$ and $w_{2}^{*}$ that maximizes $\pi_{m}$, satisfying the first order condition $\frac{\partial \pi_{m}}{\partial w_{1}}=0$ and $\frac{\partial \pi_{m}}{\partial w_{2}}=0$, we can obtain the unique optimal 

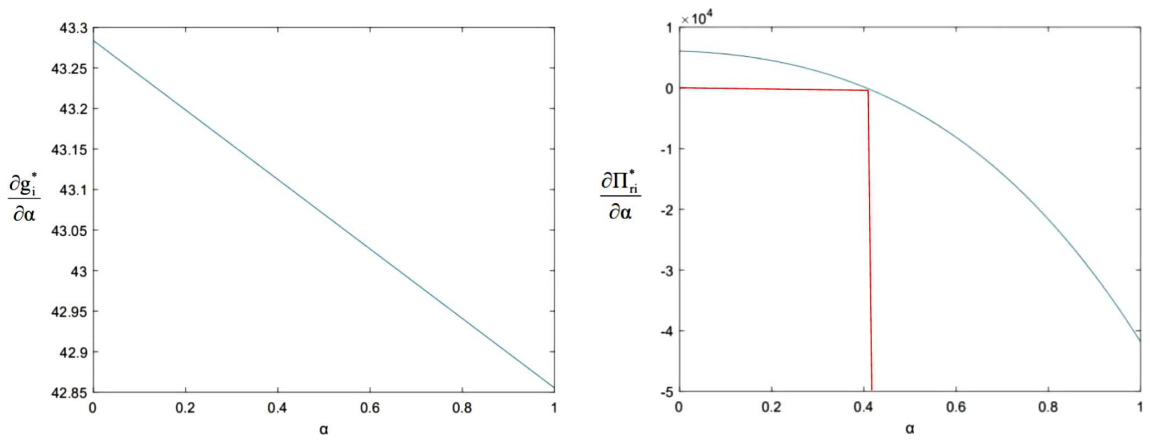

FiguRE 1. The impact of overconfidence on homogenous retailers.

value $w_{1}^{*}(\alpha)=w_{2}^{*}(\alpha)=\frac{(1+b A)(a+p A-\lambda p A)+A(c+b p A)(1-\lambda)}{2 A(1+b A)(1-\lambda)}$, substituting $w_{i}^{*}(\alpha)$ into $g_{i}^{*}(\alpha)=\frac{\left(p-w_{i}\right)(1+\alpha)}{\theta}$, obtaining the optimal greenness level $g_{1}^{*}(\alpha)=g_{2}^{*}(\alpha)=\frac{A(1-\lambda)(p-c)-a(1+b A)}{2(1+b A)(1-\lambda)}$.

(b) The difference in optimal greenness level between two homogenous retailers and two unbiased retailers is $g_{i}^{*}(\alpha)-g_{i}^{*}=\frac{A(1-\lambda)(p-c)-a(1+b A)}{2(1+b A)(1-\lambda)}-\left(\frac{(p-c) / \theta}{2(1+b / \theta)}-\frac{a}{2(1-\lambda)}\right)=\frac{(1 / \theta)(p-c)(1-\lambda) \alpha}{2(1-\lambda)(1+b / \theta)(1+b(1+\alpha) / \theta)}>0$.

In Proposition 4.1, we have pointed out the greenness competition decreases the products' greenness level, while Proposition 4.2(b) reveals that overconfidence is conducive to the greenness level of fashion products, it reveals that overconfidence can compensate the negative impact of retailers' competition on the products' greenness level.

In order to develop insight into the impacts of overconfidence, we next use numerical examples to carry out practical operations. Referring to Bernstein and Federgruen [1], the default values of numerical examples in this section are set as $a=13, \theta=1.25, \lambda=0.235, c=2.5, p=50, b=0.7$ respectively.

Based on the optimal wholesale price and greenness level, we can obtain two retails' resulting expected profit, as follows

$$
\pi_{r i}^{*}=\left(p-w_{i}^{*}\right)\left(a+g_{i}^{*}-\lambda g_{3-i}^{*}\right)-\theta g_{i}^{* 2} / 2 .
$$

For searching the impacts of overconfidence on greenness level and resulting expected profit of overconfident retailers, we analysis the first derivative of the optimal greenness level $\frac{\partial g_{i}^{*}(\alpha)}{\partial \alpha}$ and retailers' resulting expected profit $\frac{\partial \pi_{r i}^{*}}{\partial \alpha}$, the result of a numerical example is shown in Figure 1.

As shown in Figure 1, no matter how overconfident the retailer is, the derivative of the optimal green level $\frac{\partial g_{i}^{*}(\alpha)}{\partial \alpha}>0$, i.e. as the retailer's overconfidence increases, the greenness level of fashion products increases. It is in line with intuition that overconfident retailers overestimate the impact of greenness on demand, so they tend to increase their products' greenness level to get higher sales volume.

However, overconfidence is not always beneficial to the retailer's resulting expected profit. Figure 1 shows that if overconfidence is at a low level $(\alpha<0.42)$ in the numerical example), the retailers' overconfidence boosts resulting expected profit, while it would hurt retailers' resulting expected profit at a high level $(\alpha>0.42)$. When interpreting a high level of overconfidence is detrimental to retailers' resulting expected profit, a possible reason is that the high level of overconfidence leads to high level of products' greenness, and it would increase retailers' green product development investment cost $\theta g_{i}^{2} / 2$, then the retailers' resulting expected profit declines. Thus, a low level of overconfidence is not only beneficial to the products' greenness, but also conducive to retailers' resulting expected profit. 
Hence, in a fashion supply chain, the retailers' bias of overestimating the impact of greenness on demand could be a a positive force to speed up the greening of fashion products, and an overconfident retailer is not destined to receive a smaller resulting expected profit than the unbiased retailer.

\subsection{Two heterogeneous retailers}

In this part, we extend our analysis to the scenario of asymmetric overconfidence, that is, the two retailers have the different overconfidence level, we assume the overconfidence level $\alpha_{i}$ for the retail $i$. The greennessdependent demand of retailer $i$ takes the following form.

$$
q_{i}=a+\left(1+\alpha_{i}\right) g_{i}-\left(1+\alpha_{i}\right) \lambda g_{3-i}+\left(1-\alpha_{i}\right) \varepsilon .
$$

The two heterogeneous retailers' belief expected profit functions and manufacturer's resulting expected profit function is described as follows.

$$
\begin{aligned}
\pi_{r 1}\left(\alpha_{1}\right) & =\left(p-w_{1}\right)\left(a+\left(1+\alpha_{1}\right) g_{1}-\left(1+\alpha_{1}\right) \lambda g_{2}\right)-\theta g_{1}^{2} / 2 \\
\pi_{r 2}\left(\alpha_{2}\right) & =\left(p-w_{2}\right)\left(a+\left(1+\alpha_{2}\right) g_{2}-\left(1+\alpha_{2}\right) \lambda g_{1}\right)-\theta g_{2}^{2} / 2 \\
\pi_{m} & =\left(w_{1}-c-b g_{1}\right)\left(a+g_{1}-\lambda g_{2}\right)+\left(w_{2}-c-b g_{2}\right)\left(a+g_{2}-\lambda g_{1}\right) .
\end{aligned}
$$

Proposition 4.3. The optimal wholesale price and greenness level of fashion products satisfy

$$
\begin{aligned}
& w_{1}^{*}\left(\alpha_{1,2}\right)=\frac{-2 a B+B^{2} c \lambda^{2}+A^{2} p \lambda^{2}-2 A B(c+p)-a \lambda(A+B)-B^{2} a b(2+\lambda)}{\left(\lambda^{2}-1\right)\left(4 A^{2} B^{2} b^{2}+4 A^{2} B b+4 A B^{2} b\right)+\lambda^{2}\left(A^{2}+B^{2}\right)+2 A B\left(\lambda^{2}-2\right)} \\
& +\frac{-B^{2} \lambda(c-p)-2 A B^{2} b(c+p)+A B \lambda^{2}(c+p)-A B a b(3 \lambda+2)-A B \lambda(p-c)}{\left(\lambda^{2}-1\right)\left(4 A^{2} B^{2} b^{2}+4 A^{2} B b+4 A B^{2} b\right)+\lambda^{2}\left(A^{2}+B^{2}\right)+2 A B\left(\lambda^{2}-2\right)} \\
& +\frac{-4 A^{2} B b p\left(1-\lambda^{2}\right)-4 A^{2} B^{2} b^{2} p\left(1-\lambda^{2}\right)-2 A B^{2} a b^{2}(1+\lambda)+2 A B^{2} b \lambda^{2}(c+p)}{\left(\lambda^{2}-1\right)\left(4 A^{2} B^{2} b^{2}+4 A^{2} B b+4 A B^{2} b\right)+\lambda^{2}\left(A^{2}+B^{2}\right)+2 A B\left(\lambda^{2}-2\right)} \\
& w_{2}^{*}\left(\alpha_{1,2}\right)=\frac{-2 A a+A^{2} c \lambda^{2}+B^{2} p \lambda^{2}-2 A B(c+p)-a \lambda(A+B)-A^{2} a b(2+\lambda)}{\left(\lambda^{2}-1\right)\left(4 A^{2} B^{2} b^{2}+4 A^{2} B b+4 A B^{2} b\right)+\lambda^{2}\left(A^{2}+B^{2}\right)+2 A B\left(\lambda^{2}-2\right)} \\
& +\frac{-A^{2} \lambda(c-p)-2 A^{2} B b(c+p)+A B \lambda^{2}(c+p)-A B a b(2+3 \lambda)-A B \lambda(p-c)}{\left(\lambda^{2}-1\right)\left(4 A^{2} B^{2} b^{2}+4 A^{2} B b+4 A B^{2} b\right)+\lambda^{2}\left(A^{2}+B^{2}\right)+2 A B\left(\lambda^{2}-2\right)} \\
& +\frac{-4 A B^{2} b p\left(1-\lambda^{2}\right)-4 A^{2} B^{2} b^{2} p\left(1-\lambda^{2}\right)-2 A^{2} B a b^{2}(1+\lambda)+2 A^{2} B b \lambda^{2}(c+p)}{\left(\lambda^{2}-1\right)\left(4 A^{2} B^{2} b^{2}+4 A^{2} B b+4 A B^{2} b\right)+\lambda^{2}\left(A^{2}+B^{2}\right)+2 A B\left(\lambda^{2}-2\right)} \\
& g_{1}^{*}\left(\alpha_{1,2}\right)=\frac{A\left(2 A B^{2} b p \lambda^{2}-2 A B^{2} b p-2 A B^{2} b \lambda^{2} c+\lambda^{2} B^{2} p A B \lambda^{2} p\right.}{\left(\lambda^{2}-1\right)\left(4 A^{2} B^{2} b^{2}+4 A^{2} B b+4 A B^{2} b\right)+\lambda^{2}\left(A^{2}+B^{2}\right)+2 A B\left(\lambda^{2}-2\right)} \\
& +\frac{-2 A B p+2 a B-B^{2} c \lambda^{2}+2 A B c+a \lambda(A+B)+B^{2} a b(2+\lambda)+B^{2} \lambda(c-p)}{\left(\lambda^{2}-1\right)\left(4 A^{2} B^{2} b^{2}+4 A^{2} B b+4 A B^{2} b\right)+\lambda^{2}\left(A^{2}+B^{2}\right)+2 A B\left(\lambda^{2}-2\right)} \\
& +\frac{2 A B^{2} b c-A B \lambda^{2} c+A B a b(3 \lambda+2)+A B \lambda(p-c)+A B^{2} a b^{2}(1+\lambda)}{\left(\lambda^{2}-1\right)\left(4 A^{2} B^{2} b^{2}+4 A^{2} B b+4 A B^{2} b\right)+\lambda^{2}\left(A^{2}+B^{2}\right)+2 A B\left(\lambda^{2}-2\right)} \\
& g_{2}^{*}\left(\alpha_{1,2}\right)=\frac{B\left(2 A^{2} B b p \lambda^{2}-2 A^{2} B b p+A^{2} B b c\left(1-\lambda^{2}+\lambda^{2} A^{2} p+A B \lambda^{2} p\right.\right.}{\left(\lambda^{2}-1\right)\left(4 A^{2} B^{2} b^{2}+4 A^{2} B b+4 A B^{2} b\right)+\lambda^{2}\left(A^{2}+B^{2}\right)+2 A B\left(\lambda^{2}-2\right)} \\
& +\frac{-2 A B p+2 A a-A^{2} c \lambda^{2}+2 A B c+a \lambda(A+B)+A^{2} a b(2+\lambda)+A^{2} \lambda(c-p)}{\left(\lambda^{2}-1\right)\left(4 A^{2} B^{2} b^{2}+4 A^{2} B b+4 A B^{2} b\right)+\lambda^{2}\left(A^{2}+B^{2}\right)+2 A B\left(\lambda^{2}-2\right)} \\
& +\frac{2 A^{2} B b c-A B \lambda^{2} c+A B a b(3 \lambda+2)+A B \lambda(p-c)+A^{2} B a b^{2}(1+\lambda)}{\left(\lambda^{2}-1\right)\left(4 A^{2} B^{2} b^{2}+4 A^{2} B b+4 A B^{2} b\right)+\lambda^{2}\left(A^{2}+B^{2}\right)+2 A B\left(\lambda^{2}-2\right)}
\end{aligned}
$$

where $A=\frac{1+\alpha_{1}}{\theta}, B=\frac{1+\alpha_{2}}{\theta}$. 

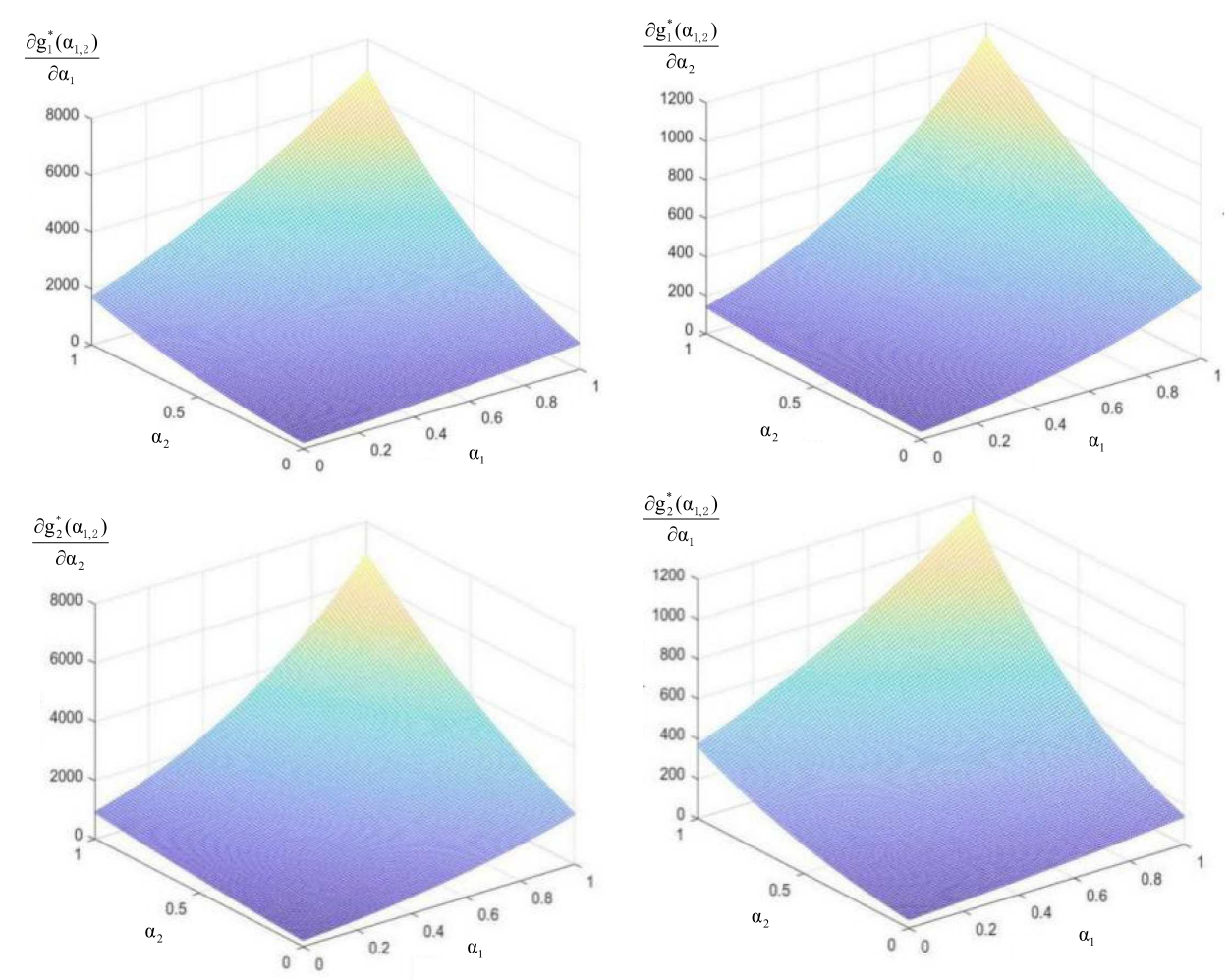

FIGURE 2. The impact of overconfidence on optimal greenness level of heterogeneous retailers.

Proof. Similar to the proof of Proposition 4.1, we know that there exists a unique solution for a given $g_{i}^{*}\left(\alpha_{1,2}\right)$ that maximizes $\pi_{r i}\left(\alpha_{1,2}\right)$, and the unique optimal value of $g_{i}^{*}\left(\alpha_{1,2}\right)$ satisfies the condition $\frac{\partial \pi_{r_{i}}\left(\alpha_{1,2}\right)}{\partial g_{i}\left(\alpha_{1,2}\right)}=(p-$ $\left.w_{i}\right)\left(1+\alpha_{i}\right)-\theta g_{i}\left(\alpha_{1,2}\right)=0$, obtaining the optimal greenness level $g_{i}^{*}\left(\alpha_{1,2}\right)=\frac{\left(p-w_{i}\right)\left(1+\alpha_{i}\right)}{\theta}$.

Next, we substitute $g_{i}^{*}\left(\alpha_{1,2}\right)$ into the $\pi_{m}$, similarly, there exists a unique solution for given $w_{1}^{*}$ and $w_{2}^{*}$ that maximizes $\pi_{m}$, by solving the first order condition $\frac{\partial \pi_{m}}{\partial w_{1}}=0$ and $\frac{\partial \pi_{m}}{\partial w_{2}}=0$, we can obtain the unique optimal value $w_{i}^{*}\left(\alpha_{1,2}\right)$,then substituting $w_{i}^{*}\left(\alpha_{1,2}\right)$ into $g_{i}^{*}\left(\alpha_{1,2}\right)=\frac{\left(p-w_{i}\right)\left(1+\alpha_{i}\right)}{\theta}$ to obtain the retailer $i$ 's optimal greenness level $g_{i}^{*}\left(\alpha_{1,2}\right)$.

In the scenario of asymmetric overconfidence, the retailer's optimal greenness level depends on both $\alpha_{1}$ and $\alpha_{2}$, we use numerical examples to argue the effects of overconfidence. The first derivative of $g_{i}^{*}\left(\alpha_{1,2}\right)$ with respect to $\alpha_{1}$ and $\alpha_{2}$ show the impacts of the retailer self and competitor's bias on products' greenness. As shown in Figure 2, $\frac{\partial g_{i}^{*}\left(\alpha_{1,2}\right)}{\partial \alpha_{i}}>0$ and $\frac{\partial g_{i}^{*}\left(\alpha_{1,2}\right)}{\partial \alpha_{3-i}}>0$, i.e. the retailer with higher level of overconfidence determines higher greenness level of its fashion products, and as its competitor's overconfidence increases, the retailer's products' greenness level increases. This leads to an unexpected but interesting result that the retailer's overconfidence is not only conducive to the greenness level of its own fashion products, but also beneficial to the greenness level of its rival's products.

Given $w_{i}^{*}\left(\alpha_{1,2}\right)$ and $g_{i}^{*}\left(\alpha_{1,2}\right)$, we can obtain the two retailers' resulting expected profit $\pi_{r i}^{*}$, as follows

$$
\pi_{r i}^{*}=\left(p-w_{i}^{*}\left(\alpha_{1,2}\right)\right)\left(a+g_{i}^{*}\left(\alpha_{1,2}\right)-\lambda g_{3-i}^{*}\left(\alpha_{1,2}\right)\right)-\theta g_{i}^{* 2}\left(\alpha_{1,2}\right) / 2 .
$$



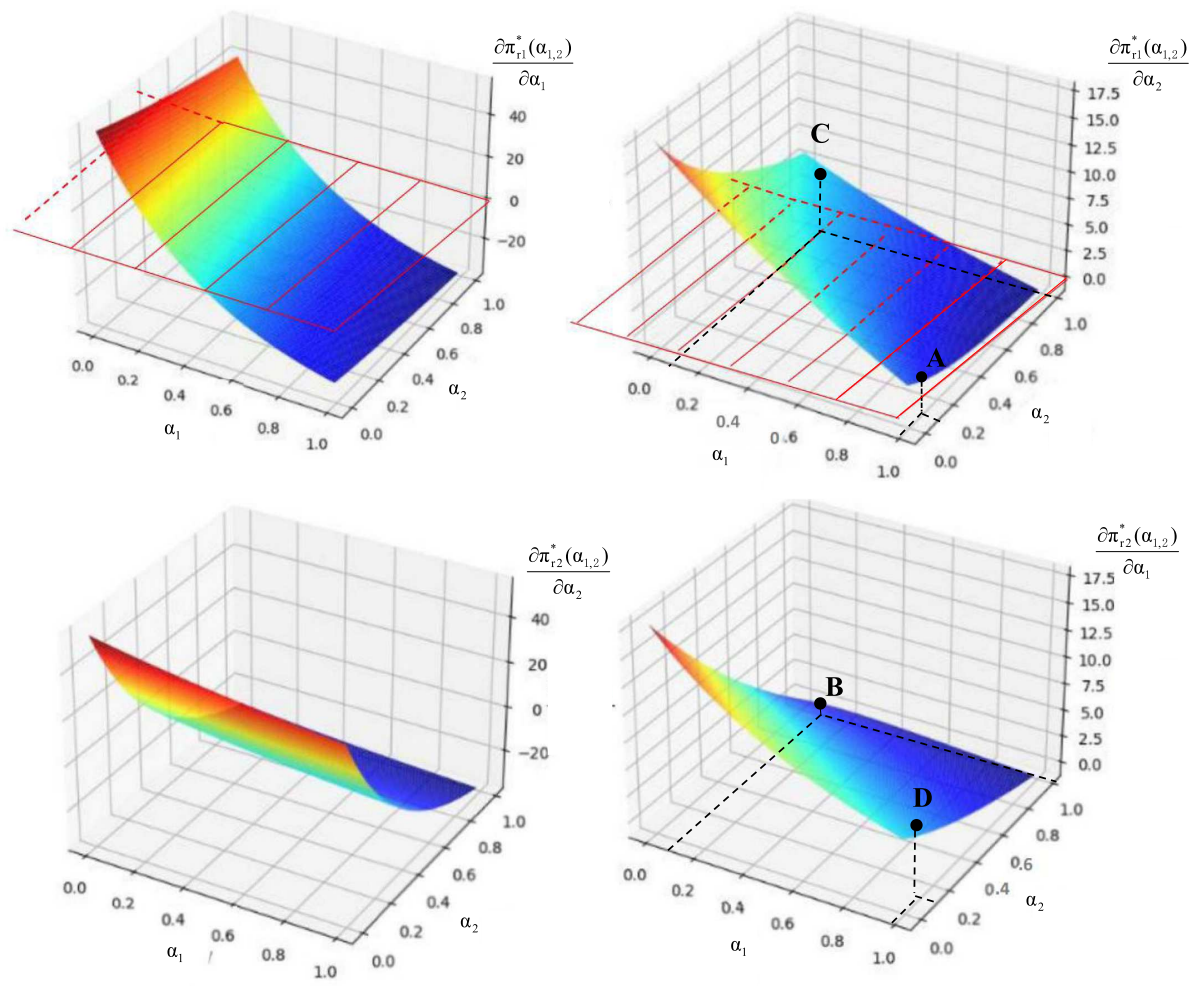

FiguRE 3. The impact of overconfidence on resulting expected profits of heterogeneous retailers.

The resulting expected profit of the retailer is depended on its own and competitor's overconfidence level. We calculate the first derivative of resulting expected profit $\frac{\pi_{r i}^{*}\left(\alpha_{1,2}\right)}{\alpha_{i}}$ and $\frac{\pi_{r i}^{*}\left(\alpha_{1,2}\right)}{\alpha_{3-i}}$ to discuss the impacts of overconfidence on profit, as shown in Figure 3.

First, the images of $\frac{\partial \pi_{r i}^{*}\left(\alpha_{1,2}\right)}{\partial \alpha_{i}}$ imply that a low level of retailer's overconfidence benefits its resulting expected profit, however, a high level of overconfidence hurts its expected profit, which is similar to the effect of overconfidence in the scenario of symmetric overconfidence.

Second, although the retailer's overconfidence has a straightforward impact on its resulting expected profit, the effect of the competitor's overconfidence is more complex. The impact of competitor's overconfidence on the retailer's profit depends on the retailer's own overconfidence level. As shown in Figure 3, the first derivative of resulting expected profit of points $A$ and $B \frac{\partial \pi_{r i}^{*}\left(\alpha_{1,2}\right)}{\partial \alpha_{3-i}}>0$, that means, in the high margin setting of the retailer's overconfidence, although the competitor's overconfidence is at a quite low level, it still has a negative impact on the retailer's profit. On the contrary, it can be seen from points $C$ and $D$ that the highest level of the competitor's overconfidence can be beneficial to the retailer's profit if the retailer's overconfidence is at a very low level. Thus, regardless of the level of competitor's overconfidence, if a fashion retailer has a low level of overconfidence, the two retailers' biases both benefit the retailer's profit. On the contrary, if a fashion retailer's overconfidence is relatively high, overconfidence of the two retailers hurts the retailer's profit.

\subsection{An extreme scenario}

In this scenario, we assume one of the retailers is unbiased, and it has an advantage of information, it is informed of the competitor's overconfidence. Within the game, it can optimize his goal based on using 
information to predict the competitor's decision. Ironically, we show that, the unbiased fashion retailer can still earn less than its biased competitor.

We define Retailer 1 is the overconfident fashion retailer who overestimating customer sensitivity to product greenness, its overconfidence level is $\alpha_{1}$, and Retailer 2 is unbiased and also fully informed of its rival's overconfidence. During the game, Retailer 1 believes its judgment is correct, and supposes Retailer 2 makes the same decision, so Retailer 1 determines its products' greenness level based on the following game

$$
\begin{aligned}
\pi_{r_{1}}\left(\alpha_{1}\right) & =\left(p-w_{1}\right)\left(a+\left(1+\alpha_{1}\right) g_{1}-\left(1+\alpha_{1}\right) \lambda g_{2}\right)-\theta g_{1}^{2} / 2 \\
\pi_{r_{2}}\left(\alpha_{1}\right) & =\left(p-w_{2}\right)\left(a+\left(1+\alpha_{1}\right) g_{2}-\left(1+\alpha_{1}\right) \lambda g_{1}\right)-\theta g_{2}^{2} / 2 \\
\pi_{m} & =\left(w_{1}-c-b g_{1}\right)\left(a+g_{1}-\lambda g_{2}\right)+\left(w_{2}-c-b g_{2}\right)\left(a+g_{2}-\lambda g_{1}\right) .
\end{aligned}
$$

From Proposition 4.2, we can obtain Retail 1's optimal wholesale price

$$
w_{1}^{*}\left(\alpha_{1}\right)=w_{2}^{*}\left(\alpha_{1}\right)=\frac{(1+b A)(a+p A-\lambda p A)+A(c+b p A)(1-\lambda)}{2 A(1+b A)(1-\lambda)}
$$

where $A=\frac{1+\alpha_{1}}{\theta}$, and the optimal products' greenness level of Retailer 1

$$
g_{1}^{*}\left(\alpha_{1}\right)=\frac{A(1-\lambda)(p-c)-a(1+b A)}{2(1+b A)(1-\lambda)} .
$$

Since Retailers 2 has an information advantage, it can anticipate the decision-making process of Retailers 1 , Retailers 2 predicts the $w_{1}^{*}\left(\alpha_{1}\right)$ and $g_{1}^{*}\left(\alpha_{1}\right)$ of Retailer 1 , then maximizes its resulting expected profit $\pi_{r_{2}}$, where

$$
\pi_{r_{2}}=\left(p-w_{2}^{*}\left(\alpha_{1}\right)\right)\left(a+g_{2}-\lambda g_{1}^{*}\left(\alpha_{1}\right)\right)-\theta g_{2}^{2} / 2 .
$$

Retailer 2 obtains its optimal products' greenness level $g_{2}^{*}\left(\alpha_{1}\right)=\frac{A(1-\lambda)(p-c)-a(1+b A)}{2 \theta A(1+b A)(1-\lambda)}$.

Proposition 4.4. (a) The fashion products designed by an overconfident retailer is greener than the unbiased retailer's.

(b) The unbiased fashion retailer who has an advantage of information can earn a lower resulting expected profit than its overconfident rival.

Proof. (a) The second derivative of $\pi_{r_{2}}$ with respect to $g_{2}$ is $-\theta<0$, it implies that $\pi_{r_{2}}$ is concave in $g_{2}$, so there exists a unique solution for a given $g_{2}^{*}\left(\alpha_{1}\right)$ that maximizes $\pi_{r_{2}}=\left(p-w_{2}^{*}\left(\alpha_{1}\right)\right)\left(a+g_{2}-\lambda g_{1}^{*}\left(\alpha_{1}\right)\right)-\theta g_{2}^{2} / 2$, the unique optimal value of $g_{2}^{*}\left(\alpha_{1}\right)$ must satisfy the condition $\frac{\partial \pi_{r_{2}}}{\partial g_{2}\left(\alpha_{1}\right)}=\left(p-w_{2}^{*}\left(\alpha_{1}\right)\right)-\theta g_{2}=0$, from which we obtain $g_{2}^{*}\left(\alpha_{1}\right)=\frac{p-w_{2}^{*}\left(\alpha_{1}\right)}{\theta}=\frac{A(1-\lambda)(p-c)-a(1+b A)}{2 \theta A(1+b A)(1-\lambda)}$. The optimal products' greenness level of Retailer 1 $g_{1}^{*}\left(\alpha_{1}\right)=\frac{A(1-\lambda)(p-c)-a(1+b A)}{2(1+b A)(1-\lambda)}$, so $g_{2}^{*}\left(\alpha_{1}\right)=\frac{1}{\theta A} g_{1}^{*}\left(\alpha_{1}\right)$, since $A=\frac{1+\alpha_{1}}{\theta}$, and $\alpha_{1}$ ranges from 0 to 1 , obviously, $g_{2}^{*}\left(\alpha_{1}\right)=\frac{1}{\theta A} g_{1}^{*}\left(\alpha_{1}\right)=\frac{1}{1+\alpha_{1}} g_{1}^{*}\left(\alpha_{1}\right)<g_{1}^{*}\left(\alpha_{1}\right)$.

(b) Then we prove Proposition 4.4(b), from the proof of Proposition 4.2, we can obtain $g_{1}^{*}\left(\alpha_{1}\right)=A\left(p-w_{1}^{*}\left(\alpha_{1}\right)\right)$, substituting $g_{1}^{*}\left(\alpha_{1}\right)=A\left(p-w_{1}^{*}\left(\alpha_{1}\right)\right)$ and $g_{2}^{*}\left(\alpha_{1}\right)=\frac{p-w_{2}^{*}\left(\alpha_{1}\right)}{\theta}$ into retailers' resulting expected profit $\pi_{r_{i}}=$ $\left(p-w_{i}^{*}\left(\alpha_{1}\right)\right)\left(a+g_{i}-\lambda g_{3-i}\right)-\theta g_{i}^{2} / 2$, obtain the resulting expected profit of Retailer $i$.

$$
\begin{aligned}
& \pi_{r_{1}}^{*}=\left(\left(p-w_{1}^{*}\left(\alpha_{1}\right)\right)\left(a+A\left(p-w_{1}^{*}\left(\alpha_{1}\right)\right)-\frac{\lambda}{\theta}\left(p-w_{2}^{*}\left(\alpha_{1}\right)\right)\right)-\frac{\theta}{2} A^{2}\left(p-w_{1}^{*}\left(\alpha_{1}\right)\right)^{2}\right) \\
& \pi_{r_{2}}^{*}=\left(\left(p-w_{2}^{*}\left(\alpha_{1}\right)\right)\left(a+\frac{1}{\theta}\left(p-w_{2}^{*}\left(\alpha_{1}\right)\right)-\lambda A\left(p-w_{1}^{*}\left(\alpha_{1}\right)\right)\right)-\frac{\theta}{2} \frac{1}{\theta^{2}}\left(p-w_{2}^{*}\left(\alpha_{1}\right)\right)^{2}\right) .
\end{aligned}
$$




$$
\begin{aligned}
& \text { Compare } \pi_{r_{1}}^{*} \text { with } \pi_{r_{2}}^{*} \text { to obtain the value of } \pi_{r_{1}}^{*}-\pi_{r_{2}}^{*} \text {. } \\
& \qquad \begin{aligned}
\pi_{r_{1}}^{*}-\pi_{r_{2}}^{*}= & \left(\left(p-w_{1}^{*}\left(\alpha_{1}\right)\right)\left(a+A\left(p-w_{1}^{*}\left(\alpha_{1}\right)\right)-\frac{\lambda}{\theta}\left(p-w_{2}^{*}\left(\alpha_{1}\right)\right)\right)-\frac{\theta}{2} A^{2}\left(p-w_{1}^{*}\left(\alpha_{1}\right)\right)^{2}\right) \\
& -\left(\left(p-w_{2}^{*}\left(\alpha_{1}\right)\right)\left(a+\frac{1}{\theta}\left(p-w_{2}^{*}\left(\alpha_{1}\right)\right)-\lambda A\left(p-w_{1}^{*}\left(\alpha_{1}\right)\right)\right)+\frac{\theta}{2} \frac{1}{\theta^{2}}\left(p-w_{2}^{*}\left(\alpha_{1}\right)\right)^{2}\right) \\
= & (p-w)^{2} \frac{\alpha_{1}(1+\lambda)}{\theta}-(p-w)^{2} \frac{\left(1+\alpha_{1}\right)^{2}-1}{2 \theta} \\
= & (p-w)^{2} \frac{\alpha_{1}\left(2 \lambda-\alpha_{1}\right)}{2 \theta} .
\end{aligned}
\end{aligned}
$$

If $\alpha_{1}<2 \lambda, \pi_{r_{1}}^{*}-\pi_{r_{2}}^{*} \geq 0$, which implies if Retailer 1's overconfidence level is relatively low, Retailer 1 can earn more than Retailers 2 who is unbiased and has an advantage of information.

The above proposition shows that overconfidence drives a fashion retailer to promote the greenness level of fashion products. Moreover, although the unbiased fashion retailer can increase its resulting expected profit by reacting optimally, it still can earn a lower profit than its overconfident rival.

\section{Conclusions}

In this paper, we discuss the impacts of two competing retailers' overconfidence on products' greenness and retailers' expected profit in a fashion supply chain, overconfidence in this context is defined as a cognitive bias of overestimating the impact of greenness on demand and underestimating market demand variance.

We first consider a scenario of two unbiased competing retailers and one rational manufacturer in a fashion supply chain, we find the competition on fashion products' greenness between retailers hurts the optimal greenness level.

Then we incorporate the notion of overconfidence into competition. In the scenario that the two retailers have the same level of overconfidence, we discover the retailers' overconfidence is conducive to the improvement of fashion products' greenness level, and this bias is not destined to a lower resulting expected profit of the overconfident retailer, a low level of overconfidence benefits the retailer's profit. In the scenario of two heterogeneous retailers, it first shows the retailer's overconfidence is not only conducive to the greenness level of their own fashion products, but also benefits to its rivals' products' greenness. Second, the retailer's resulting expected profit is affected by overconfidence of itself and its competitor. If the retailer's own overconfidence is at a low level, the two retailers' biases both benefit the retailer's profit, and if the retailer's overconfidence is relatively high, its and its competitor's overconfidence hurts its profit.

At last, we consider an extreme case to show the advantage attributed to overconfidence is robust. In this case, Retailer 1 is overconfident about customer sensitivity to products' greenness, while Retailer 2 is unbiased and fully cognizant of its rival's overconfidence. We find this bias drives the overconfident fashion retailer to promote the greenness level of fashion products, and the unbiased fashion retailer can earn a lower resulting expected profit than its overconfident rival although it has an advantage of information and increases its expected profit by reacting optimally.

The authors in the past have regarded multiple negative effects of overconfidence, such as one overconfident newsvendor's expected profit decreases in its bias level [19], green optimism hurts the performance of stakeholders and the manufacturer [12]. But there are also many researches showing positive effects of this bias, for example, overconfidence has an advantage when opening an innovative business [16], the bias can be a positive force to channel performance and members [18], and the optimism about demand of one firm can gain more profit for two firms in a competitive market [11].

Our research first shows overconfidence about overestimating the impact of greenness on demand promotes the greenness level of fashion products, thus, from the perspective of environmental protection, this bias improves 
the green degree of fashion products and accelerates the development of sustainable fashion industry. Second, our results suggest that overconfidence is a double-edged sword for the profit of a fashion retailer. A low level of overconfidence can make a profit advantage under the competitive condition, but excessive overconfidence would damage the retailer's profit. So from a managerial standpoint, a low level of overconfidence is beneficial to retailers when launching green fashion products, it can better open up a new situation of products and seize the opportunity of market demand. However, retailers should pay special attention to excessive overconfidence. When setting up a decision-making group, a retail enterprise can improve their timeliness and innovation by adding optimistic personnel, but the unbiased and conservative personnel are also needed.

While our model captures the essential elements to study the product greenness competition game of overconfident fashion retailers in a fashion supply chain, other aspects in real world should be considered in the future. First, in practice, the competition between fashion retailers not only for product greenness but also for retail prices, therefore, further research can explore the impact of overconfidence in the setting of joint competition on product greenness and retail price. Second, this paper focuses on the product greenness competition game at the retail level. In a fashion supply chain, manufacturers could also be overconfident and various powerful manufacturers have direct channels to consumers, thus, manufacturers with overconfidence deserve further research. Third, the expression of overconfidence is various, overconfidence could affect other decisions made by fashion retailers and manufacturers, so it will be interesting to explore the impacts of overconfidence defined as other manifestations of fashion supply chains.

Acknowledgements. This work is partly supported by the National Natural Science Foundation of China under Grants 71671055,72071056 and 71971075 . This work is also partly supported by the National Key Research and Development Program of China 2019YFE0110300.

\section{REFERENCES}

[1] F. Bernstein and A. Federgruen, Coordination mechanisms for supply chains under price and service competition. Manuf. Serv. Oper. Manage. 9 (2007) 242-262.

[2] H. Chen, Y.F. Chen, C.-H. Chiu and S. Sethi, Coordination mechanism for the supply chain with leadtime consideration and price-dependent demand. Eur. J. Oper. Res. 203 (2009) 70-80.

[3] K. Chen, X. Song, X. Wang and M. Huang, Joint pricing and production decisions with the overconfident sales agent. J. Syst. Manage. 25 (2016) 468-474.

[4] B. Cheng, R. Li, X. Zhu, M. Zhou and X. Cao, Optimal decision in MC supply chain with overconfident retailer based on the newsvendor model. RAIRO-Oper. Res. 55 (2021) 1325-1341.

[5] K. Cowan and T. Kinley, Green spirit: consumer empathies for green apparel. Int. J. Consum. Stud. 38 (2014) $493-499$.

[6] W. Ding, Study on green ecology-oriented fashion design. Appl. Mech. Mater. 340 (2013) 179-184.

[7] Y.-N. Fung, H.-L. Chan, T.-M. Choi and R. Liu, Sustainable product development processes in fashion: supply chains structures and classifications. Int. J. Prod. Econ. 231 (2021) 0925-5273.

[8] H. Goworek, T. Fisher, T. Cooper, S. Woodward and A. Hiller, The sustainable clothing market: an evaluation of potential strategies for UK retailers. Int. J. Retail Distrib. Manage. 40 (2012) 935-955.

[9] S. Guo, T.-M. Choi and B. Shen, Green product development under competition: a study of the fashion apparel industry. Eur. J. Oper. Res. 280 (2020) 523-538.

[10] N. Izabela, M. Sani, S. Eryk and S. Subrata, Impact of strategic cooperation under competition on green product manufacturing. Sustainability 12 (2020) 10248.

[11] B. Jiang and C. Liu, Managerial optimism in a competitive market. Prod. Oper. Manage. Soc. 28 (2019) 833-846.

[12] M. Jin, X. Zhang, Y. Xiong and Y. Zhou, Implications of green optimism upon sustainable supply chain management. Eur. J. Oper. Res. 295 (2021) 131-139.

[13] S. Karray and G. Martín-Herrán, Fighting store brands through the strategic timing of pricing and advertising decisions. Eur. J. Oper. Res. 275 (2018) 635-647.

[14] S. Kim, E. Ko and S.J. Kim, Fashion brand green demarketing: effects on customer attitudes and behavior intentions. J. Global Fashion Market. 9 (2018) 364-378.

[15] S.N. Kirshner and L. Shao, The overconfident and optimistic price-setting newsvendor. Eur. J. Oper. Res. 277 (2019) $166-173$.

[16] P. Koellinger, M. Minniti and C. Schade, "I think I can, I think I can": overconfidence and entrepreneurial behavior. J. Econ. Psychol. 28 (2007) 502-527.

[17] E.-J. Lee, H. Choi, J. Han, D.H. Kim, E. Ko and K.H. Kim, How to "Nudge" your consumers toward sustainable fashion consumption: an fMRI investigation. J. Bus. Res. 117 (2020) 642-651.

[18] M. Li, Overconfident distribution channels. Prod. Oper. Manage. Soc. 28 (2019) 1347-1365. 
[19] M. Li, N.C. Petruzzi and J. Zhang, Overconfident competing newsvendors. Manage. Sci. 63 (2016) $2637-2646$.

[20] Z. Li, H. Zhu, Q. Meng and P. Shen, Green product competition-diffusion considering consumer network. Syst. Eng. 36 (2018) $106-112$.

[21] J. Li, M. Li and X. Zhao, Transshipment between overconfident newsvendors. Prod. Oper. Manage. Soc. 30 (2021) $2803-2813$.

[22] J. Liu, W. Jiang and Y. Tang, The supply chain coordination based on carbon reduction of overconfident manufacturer. J. Jiangxi Normal Univ. (Nat. Sci. Ed.) 42 (2018) 203-207.

[23] J.M. Merigó and J.-B. Yang, A bibliometric analysis of operations research and management science. Omega 73 (2016) 37-48.

[24] K.K.-L. Moon, C. Youn, J.M.T. Chang and A.W. Yeung, Product design scenarios for energy saving: a case study of fashion apparel. Int. J. Prod. Econ. 146 (2013) 392-401.

[25] K. Murali, M.K. Lim and N.C. Petruzzi, The effects of ecolabels and environmental regulation on green product development. Manuf. Serv. Oper. Manage. 21 (2018) 519-535.

[26] H.L. Neumann, L.M. Martinez and L.F. Martinez, Sustainability efforts in the fast fashion industry: consumer perception, trust and purchase intention. Sustainability Accounting Manage. Policy J. 12 (2021) 571-590.

[27] H. Reefke and D. Sundaram, Key themes and research opportunities in sustainable supply chain management-identification and evaluation. Omega 66 (2017) 195-211.

[28] R. Romero Silva and S. de Leeuw, Learning from the past to shape the future: a comprehensive text mining analysis of OR/MS reviews. Omega 100 (2020) 102388.

[29] Vandana, Ethical apparels-an innovative approach in fashion industry. ZENITH Int. J. Bus. Econ. Manage. Res. 4 (2014) $10-15$.

[30] A.T. Vogel and K. Watchravesringkan, Consumer evaluations of trend imitation: brand equity,consumer attitudes and preference. J. Prod. Brand Manage. 26 (2017) 516-527.

[31] K. White, D.J. Hardisty and R. Habib, The elusive green consumer. Harvard Bus. Rev. 97 (2019) $124-133$.

[32] M. Wiederhold and L.F. Martinez, Ethical consumer behaviour in Germany: te attitude-behaviour gap in the green apparel industry. Int. J. Consum. Stud. 42 (2018) 419-429.

[33] D. Xiao, J.X.Q. Yuan and H. Lu, Supply chain inventory strategy considering quality control under decision-maker overconfidence perspective. Chin. J. Manage. Sci. 22 (2014) 59-65.

[34] Y. Xu, Z. Liu and H. Wang, Research on supply chain incentive contract with an overconfident retailer under information asymmetry. Oper. Res. Manage. Sci. 23 (2014) 113-118.

[35] R. Yang, W. Tang and J.X. Zhang, Technology improvement strategy for green products under competition: the role of government subsidy. Eur. J. Oper. Res. 289 (2021) 553-568.

[36] H. Yu and D. Zhou, The gain/loss-sharing buyback contract coordination for a supply chain with a overconfident retailer. J. Syst. Sci. Math. Sci. 35 (2015) 121-128.

[37] Y. Zhong, Z. Liu, J. Guo and J. Li, Research on ordering decision and coordination of overconfident retailer based on newsvendor model. Oper. Res. Manage. Sci. 21 (2012) 62-66.

[38] W. Zhu and Y. He, Green product design in supply chains under competition. Eur. J. Oper. Res. 258 (2017) 165-180.

[39] X. Zhu and G. Wu, Green product diffusion: the impacts of asymmetric retailers' strategic product decisions. RAIRO-Oper. Res. 55 (2021) 1459-1486.

\section{Subscribe to Open (S2O)}

\section{A fair and sustainable open access model}

This journal is currently published in open access under a Subscribe-to-Open model (S2O). S2O is a transformative model that aims to move subscription journals to open access. Open access is the free, immediate, online availability of research articles combined with the rights to use these articles fully in the digital environment. We are thankful to our subscribers and sponsors for making it possible to publish this journal in open access, free of charge for authors.

\section{Please help to maintain this journal in open access!}

Check that your library subscribes to the journal, or make a personal donation to the $\mathrm{S} 2 \mathrm{O}$ programme, by contacting subscribers@edpsciences.org

More information, including a list of sponsors and a financial transparency report, available at: https://www. edpsciences.org/en/maths-s2o-programme 